TITLE:

\title{
Risk reduction through early assessment and integration of sustainability in design in the minerals industry
}

\author{
$\operatorname{AUTHOR}(S)$ :
}

McLellan, B.C.; Corder, G.D.

\section{CITATION:}

McLellan, B.C.... [et al]. Risk reduction through early assessment and integration of sustainability in design in the minerals industry. Journal of Cleaner Production 2013, 53 : $37-46$

ISSUE DATE:

2013-08

URL:

http://hdl.handle.net/2433/175390

\section{RIGHT:}

(C) 2012 Elsevier Ltd.; This is not the published version. Please cite only the published version.; この論文は出版社版でありません。引用の際に は出版社版をご確認ご利用ください。 
McLellan, B.C., Corder, G.D., Risk reduction through early assessment and integration of sustainability in design in the minerals industry, Journal of Cleaner Production, 53( ), 37-46 (2013) http://dx.doi.org/10.1016/j.jclepro.2012.02.014.

\title{
Risk reduction through early assessment and integration of sustainability in design in the minerals industry
}

\author{
B.C. McLellan ${ }^{1}$, G.D. Corder ${ }^{2}$ \\ ${ }^{1}$ Graduate School of Energy Science, Kyoto University, Yoshida-honmachi, Sakyo-ku, \\ Kyoto 606-8501, Japan. \\ ${ }^{2}$ The University of Queensland, Sustainable Minerals Institute, Brisbane, QLD 4072, Australia.
}

\section{Abstract}

Early integration of sustainability considerations into the design of industrial operations offers great potential for the reduction of risks associated with a project. Recent experience in the development of a practical methodology for undertaking such "design for sustainability" has illustrated this point clearly. This paper examines the generic and specific risk reduction potential of applying a sustainability-based design process. This is illustrated through the analysis of two case studies. The case studies involved base metals extraction and processing and were located in lowmid development countries. By utilizing an overarching sustainability model, it was possible to elicit risks that could affect the sustainability performance of the resulting minerals operation and consequently identify potential initiatives or strategies that could mitigate these risks. As both case study projects are at the early stages of project development, the risk mitigation initiatives or strategies can be developed in concert with the normal project development activities. As the opportunities for reducing sustainability associated risks are closely related to the project phase, the earlier (e.g. concept or pre-feasibility) such a methodology is applied in the life of a project the better. Progressing down the project life cycle (e.g. basic or detailed design), elements of flexibility are lost, and therefore the potential to derive greater sustainability benefits and minimize risk at least cost is diminished. Risk reduction through early assessment and integration of sustainability in design makes a significant contribution to the social licence to operate of the resulting operation. 
McLellan, B.C., Corder, G.D., Risk reduction through early assessment and integration of sustainability in design in the minerals industry, Journal of Cleaner Production, 53( ), 37-46 (2013) http://dx.doi.org/10.1016/j.jclepro.2012.02.014.

\section{Introduction}

Risk reduction is one of the key concerns of companies when undertaking the design and construction of new operations. This is particularly apparent in the minerals industry, where it is frequently pointed out that the majority of the high value, low risk ore deposits have already been developed $[1,2]$. The remaining deposits typically demonstrate a number of areas of risk, among which are:

- Country risk - including the stability of government and law and order, the availability of infrastructure and workforce [3];

- Environmental risk - many new high grade ore deposits are in relatively pristine areas of high natural value, or areas of high natural disaster risk, or require particularly intensive processing.

- Extra financial risk - due to the natural uncertainty of geology, the potential need for expatriate labor force, and the high cost of constructing infrastructure where there is none currently [3].

In addition to these extraordinary risks posed by the specific nature of the minerals industry, there are multiple other areas of risk, common to most industrial operations - onsite safety, process safety, economic risk and the emerging climate change risk. However, even many of the common industrial risks are exacerbated in the minerals industry, due to the sheer volume of throughput and associated flowrates of energy, reagents and waste $[4,5]$.

Risk assessment and management - especially from the perspective of health and safety - are widely applied in the minerals industry - where potential hazards are an inherent part of the operation. Health and safety, safety by design, loss prevention and risk assessment have also been a continuing focus, and represent some of the key indicators of performance for international minerals corporations [6-8]. Although difficult to prove conclusively [9], studies of the empirical evidence suggest that the increased focus of attention on hazard reduction and safety - as typified by the widespread application of Hazard and Operability (HazOp) studies in industrial processing projects - has improved the overall safety of the industry [10-15]. It has also been indicated empirically that a risk assessment based approach to safety may be one key factor in improving safety performance over compliance-based approaches [8]. This risk assessment has mainly focused on reducing risk to humans, with some environmental risk assessment being added in recent years as exemplified by the incorporation of environmental hazards into HazOp [16]. There is thus a 
McLellan, B.C., Corder, G.D., Risk reduction through early assessment and integration of sustainability in design in the minerals industry, Journal of Cleaner Production, 53( ), 37-46 (2013)

http://dx.doi.org/10.1016/j.jclepro.2012.02.014.

recognition that risk reduction processes are valuable in design - and some empirical indication that they may create positive outcomes.

In the minerals industry, with numerous exceptional risks, there is also a growing realization of the importance of enhancing the operational contribution to sustainable development (SD) - as is indicated by the large scale initiatives by mining organizations and major mining companies [17-20] and the significant research effort that has been put into this area - see for example [21-23]. The potential value that can be derived from cleaner production [24, 25], industrial ecology [26] and other technical and non-technical sustainability-related initiatives [27] has also been recognized and reporting of such initiatives and their outcomes is becoming routine, even if the effectiveness of reporting in communication and performance improvement is not always fully achieved [28]. This value can come in the form of direct financial benefit, as well as indirect cost savings, extension of mine life [21] and non-financial gains [29, 30]. However, despite the recognition of its importance and the apparent benefits of incorporating sustainability the complex nature of the concept, and the restrictions of current design and project processes - which bind the designers in terms of scope, budget and time [31] - do not facilitate its incorporation. It is within this context that the SUSOP ${ }^{\circledR}$ methodology was developed in order to fill the recognized gap between theoretical acceptance of sustainable development and practical implementation within the constraints of the minerals industry [32].

The term "sustainability risk" referring largely to the risk of adverse social and environmental impacts, has been discussed elsewhere - for example in terms of supply chain sustainability risk [33]. Hereafter we use sustainability risk or SD risk in the same sense, but with an expanded sustainability framework - the "Five Capitals" framework (including natural, social, human, financial and manufactured capitals) as our reference for examining and identifying SD risk.

Although the reduction of risk to humans is empirically understood to result from systematic incorporation of safety in design, the same premise has not been examined in regards to the potential for reducing sustainability-related risks by incorporating SD into the design process. There is thus a gap in the knowledge, which the current work intends to bridge. This paper analyses the results of research into designing more sustainable operations in the minerals industry context through the example of the SUSOP ${ }^{\circledR}$ methodology. The paper looks first at how these risks can be identified and solutions developed to reduce risk at an appropriate stage in design. It then examines how the outcomes of SUSOP ${ }^{\circledR}$ case studies have been able to reduce extraordinary risk on a broad, sustainability-focused set of categories. 
McLellan, B.C., Corder, G.D., Risk reduction through early assessment and integration of sustainability in design in the minerals industry, Journal of Cleaner Production, 53( ), 37-46 (2013) http://dx.doi.org/10.1016/j.jclepro.2012.02.014.

\section{Research methodology}

This paper seeks to answer two fundamental questions about risk in relation to sustainability in the minerals industry. Firstly, we ask what types of risk can be identified and how they can be mitigated theoretically by applying a sustainability-based design framework (SUSOP®). Secondly, through examination of the process and results of applying the SUSOP ${ }^{\circledR}$ framework, we attempt to demonstrate the relative success of the process in reducing some of the potential risks. Details on the SUSOP ${ }^{\circledR}$ framework are presented in the next section.

To answer these questions, two live SUSOP ${ }^{\circledR}$ case studies were analysed. Firstly, the theoretical risks and identification of mitigation opportunities was analysed by examining the SUSOP ${ }^{\circledR}$ framework and the generic minerals operation. This examination used a generalized flowsheet for a minerals processing operation and examined the key sources of risk that arise from the inputs, internal operations and outputs of the operation. The generic minerals operation was segregated into a mining section and primary / secondary processing section based on similarity of the operations leading to similar risk sources. This examination of hazards was further structured by applying an SD framework - the "Five Capitals" model [34]. By applying this grid of risk source and affected capital, some of the key SD risks were identified. The identified risks were used as part of the assessment of SUSOP ${ }^{\circledR}$ performance in improving SD contribution and reducing SD risk.

In the second part of the analysis, the results of the two specific case studies were analysed to identify the efficacy of sustainable design (as demonstrated using SUSOP${ }^{\circledR}$ ) as a sustainability-risk reduction tool. The identified sustainable design options that were developed using SUSOP ${ }^{\circledR}$ were analysed using a semi-quantitative assessment process during the "Analysis" and "Prioritisation" of sustainability risks and opportunities stages of the two case studies. The assessment process involved the project team (technical, environmental and community focused consultants and mining company employees, with facilitation from a SUSOP ${ }^{\circledR}$ facilitator) identifying the improvements or non-improvements associated with the sustainable design options. The project team then weighted and associated a level SD impact or risk with the base case, and with the sustainable design options using a risk-based approach on the five capitals. The risk matrix used in the assessment is presented in Table 1, where "Severity" refers to the severity of impact on a given capital and "Probability" to the anticipated probability of that impact, based on the design of the operation. Indicators of impact within each capital (for example, energy usage, impacts on water and greenhouse gas intensity) were used to produce a more detailed picture of the operation and SD improvements, and to allow the use of quantification where possible. The risk level associated with each of the 
McLellan, B.C., Corder, G.D., Risk reduction through early assessment and integration of sustainability in design in the minerals industry, Journal of Cleaner Production, 53( ), 37-46 (2013)

http://dx.doi.org/10.1016/j.jclepro.2012.02.014.

indicators was then weighted and averaged to allow the cumulative score to be appointed for each capital.

Table 1: Probability vs Severity Risk Matrix

\begin{tabular}{|c|c|c|c|c|c|c|}
\hline & & \multicolumn{5}{|c|}{ Probability } \\
\hline & & $\begin{array}{l}\text { Almost } \\
\text { certain }\end{array}$ & Likely & Possible & Unlikely & Rare \\
\hline \multirow{5}{*}{ 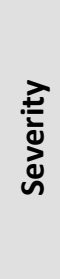 } & Highly significant & Extreme & Extreme & Extreme & High & Significant \\
\hline & Major & Extreme & Extreme & High & Significant & Moderate \\
\hline & Moderate & Extreme & High & Significant & Moderate & Low \\
\hline & Minor & High & Significant & Moderate & Low & Low \\
\hline & Low & Significant & Moderate & Low & Low & Low \\
\hline
\end{tabular}

\section{Background}

\subsection{Sustainability in design of minerals operations}

Design of minerals operations generally has not, to date, taken into account sustainability explicitly, except in a number of academic articles and approaches (e.g. - [35-37]). While not explicitly focused on sustainability as an entire, integrated concept there are however, many aspects of the design of a minerals project that could be considered to encompass elements or tools of sustainability - such as environmental impact assessment [38].

This gap in theory and application for integrating sustainability principles into the design of industrial processing operations has led to the development of the SUSOP® ${ }^{\circledR}$ framework. This framework is the outcome of a collaborative research project between industry and research organizations and, although briefly described here, more detail is available elsewhere $[29,32,39]$.

The life of a minerals operation is depicted in Figure 1. The project development cycle (vertical) shows the key steps in the development of a mineral deposit through to production and then to closure. The production cycle (horizontal) indicates the supply chain of minerals products. The application of sustainable design to a minerals operation could occur at any intersection of these two cycles. Ideally, the earlier in the project cycle, the better, in order to achieve sustainable outcomes. 
McLellan, B.C., Corder, G.D., Risk reduction through early assessment and integration of sustainability in design in the minerals industry, Journal of Cleaner Production, 53( ), 37-46 (2013) http://dx.doi.org/10.1016/j.jclepro.2012.02.014.

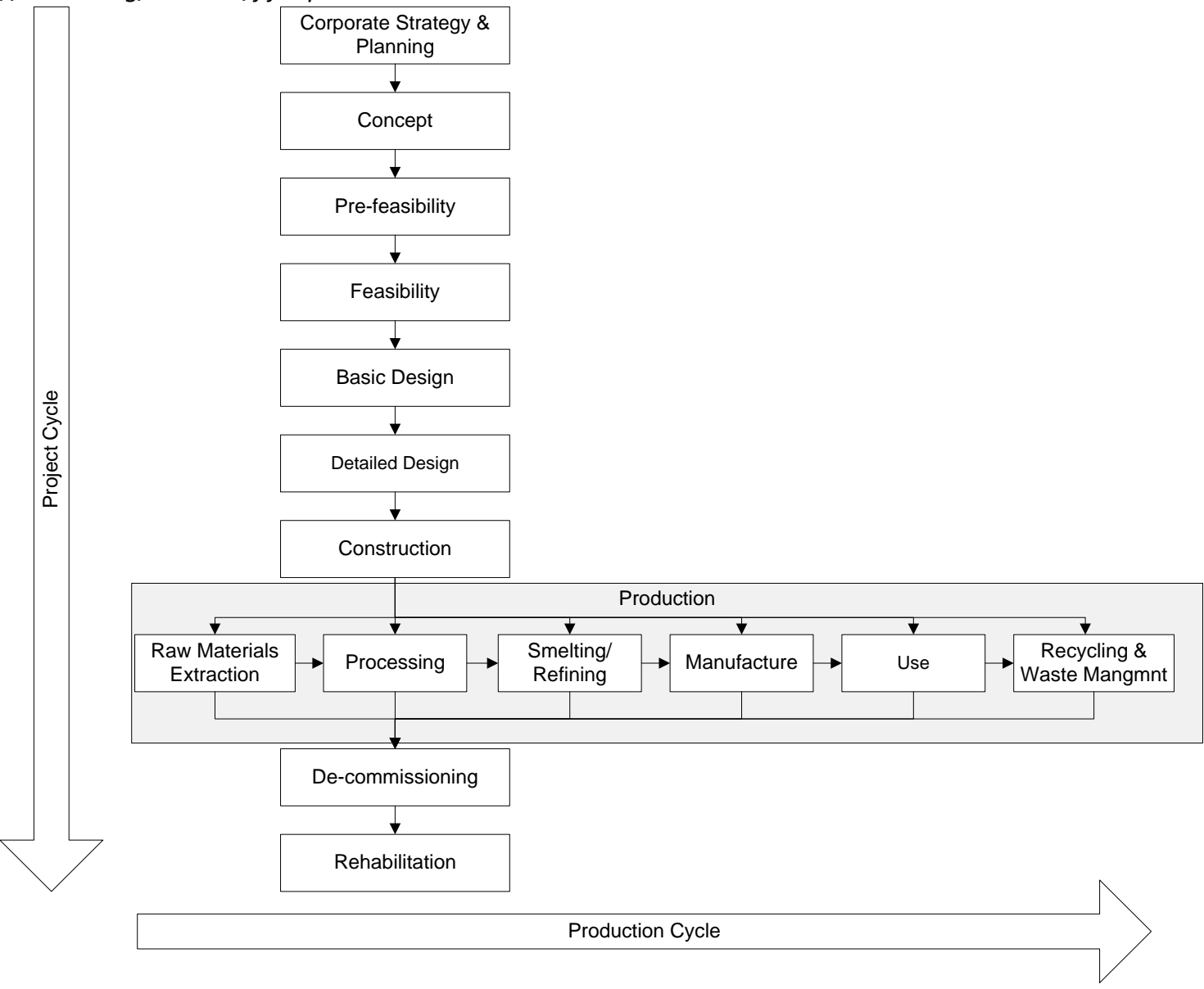

Figure 1: Project-Production Cycle

Current management of project development is highly driven by time and budget constraints, and the design of a minerals project is broken down into a number of project stages with different levels of detail and required tasks at each phase (for more detail, see for example [40]). One of the key elements in implementing more effective sustainability-based risk reduction and getting approval of the processes and outcomes from internal stakeholders is ensuring that the timing of studies align closely with the project development cycle. HazOp processes for loss prevention have been developed in this way, involving different studies at each stage of project development - with the level of detail in the study matching available project data and definition.

Likewise, the opportunities for reducing sustainability associated risk are closely related to the project phase. As the operation progresses down the project cycle, at each phase some elements of flexibility are lost, and therefore the potential to derive greater sustainable development (SD) benefits and minimize risk at least cost is diminished. Table 2 indicates where the focus of sustainability opportunities and risk identification is considered most appropriate at each of the pre- 
McLellan, B.C., Corder, G.D., Risk reduction through early assessment and integration of sustainability in design in the minerals industry, Journal of Cleaner Production, 53( ), 37-46 (2013)

http://dx.doi.org/10.1016/j.jclepro.2012.02.014.

construction project development phases, and where such identification is not relevant due to project management constraints.

Table 2: Scale of focus for SD opportunities at each project phase - after [41]

\begin{tabular}{|c|c|c|c|c|c|c|}
\hline \multicolumn{2}{|r|}{ Project Phase } & Concept & Pre-feasibility & Feasibility & $\begin{array}{c}\text { Design - } \\
\text { Basic }\end{array}$ & $\begin{array}{l}\text { Design - } \\
\text { Detailed }\end{array}$ \\
\hline \multirow{5}{*}{ 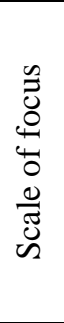 } & $\begin{array}{c}\text { Unit } \\
\text { Operation } \\
\end{array}$ & $\mathbf{X}$ & $\mathrm{O}$ & $\mathrm{O}$ & $\mathrm{O}$ & $\mathrm{O}$ \\
\hline & Plant / Area & $\mathrm{O}$ & $\mathrm{O}$ & $\mathrm{O}$ & $\mathbf{X}$ & $\mathbf{X}$ \\
\hline & Site & $\mathrm{O}$ & $\mathrm{O}$ & $\mathrm{O}$ & $?$ & $\mathrm{X}$ \\
\hline & Value Chain & $\mathrm{O}$ & $\mathrm{O}$ & $\mathrm{O}$ & $?$ & $?$ \\
\hline & External & $\mathrm{O}$ & $\mathrm{O}$ & $\mathrm{O}$ & $?$ & $\mathrm{O}$ \\
\hline
\end{tabular}

\begin{tabular}{|c|c|}
\hline $\mathrm{O}$ & Main focus of SD opportunities and risk identification \\
\hline ? & Some (minor) potential for change \\
\hline $\mathbf{X}$ & No potential for change under current project paradi \\
\hline
\end{tabular}

One example of the different approaches at different phases is when the flowsheet has been frozen (at the end of Pre-feasibility [40]). At this stage, it is no longer worthwhile (in the current project development paradigm) examining alternative flowsheets or technology that will disrupt the current layout. Thus, although some sustainability risks may be better-mitigated using alternative technology, it is highly unlikely that such alternatives will be adopted at the budget and time cost of significant re-engineering. Benefits may still be gained in examining local sourcing of consumables and workforce, or more efficient pumps, or the production impacts (embodied energy, etc.) of equipment.

By early consideration of sustainability risks in the development of a new minerals project, it is possible to derive several benefits:

- Identification of social, human and environmental issues and the development of subsequent solutions or mitigating strategies throughout the project development stages rather than managing these issues once the project is complete

- Identification of critical sustainability issues that would not necessarily be identified through the normal project management process but could result in a major business risk to the project or operation. Such issues could be feasible, both technically and financially, but could generate significant stakeholder concern or even outrage and, thus, negatively impact on the operation's social license to operate 
McLellan, B.C., Corder, G.D., Risk reduction through early assessment and integration of sustainability in design in the minerals industry, Journal of Cleaner Production, 53( ), 37-46 (2013) http://dx.doi.org/10.1016/j.jclepro.2012.02.014.

Alternative and price competitive resources may exist that could impact an operation's viability such as renewable energy, industry waste heat, re-processed industrial and residential effluents, and organic and inorganic by-products from nearby industrial operations that are not normally considered in the standard project management processes. By early identification of risks and mitigation measures, it is anticipated that the overall impact on project cost and schedule will be minimized [42].

\subsection{SUSOP ${ }^{\circledR}$ in brief}

SUSOP ${ }^{\circledR}$ is a guiding structured framework for identifying opportunities for improving sustainability outcomes and reducing risks with industrial processing operations for all stages of the project development cycle - from corporate planning, through design and operation, to decommissioning and rehabilitation stages. It comprises three major elements:

1) Sustainability opportunities and risks identification (SUSID $\left.{ }^{\mathrm{TM}}\right)$. A significant characteristic of this element is that it includes 'new ideas' generation. This is the most substantial element of SUSOP ${ }^{\circ}$ and is made up of four steps:

Step (i) Familiarisation with Sustainability Concepts and Project Context;

Step (ii) Goal Scoping and Opportunities \& Risks Identification;

Step (iii) Analysis of Sustainability Opportunities \& Risks;

Step (iv) Prioritisation of Sustainability Opportunities \& Risks.

2) Sustainable Development (SD) Assessment - to conduct a detailed evaluation of the shortlisted or high-priority opportunities and risks.

3) Decision Support - to provide assistance with decision-making at project toll gates. 
McLellan, B.C., Corder, G.D., Risk reduction through early assessment and integration of sustainability in design in the minerals industry, Journal of Cleaner Production, 53( ), 37-46 (2013)

http://dx.doi.org/10.1016/j.jclepro.2012.02.014.

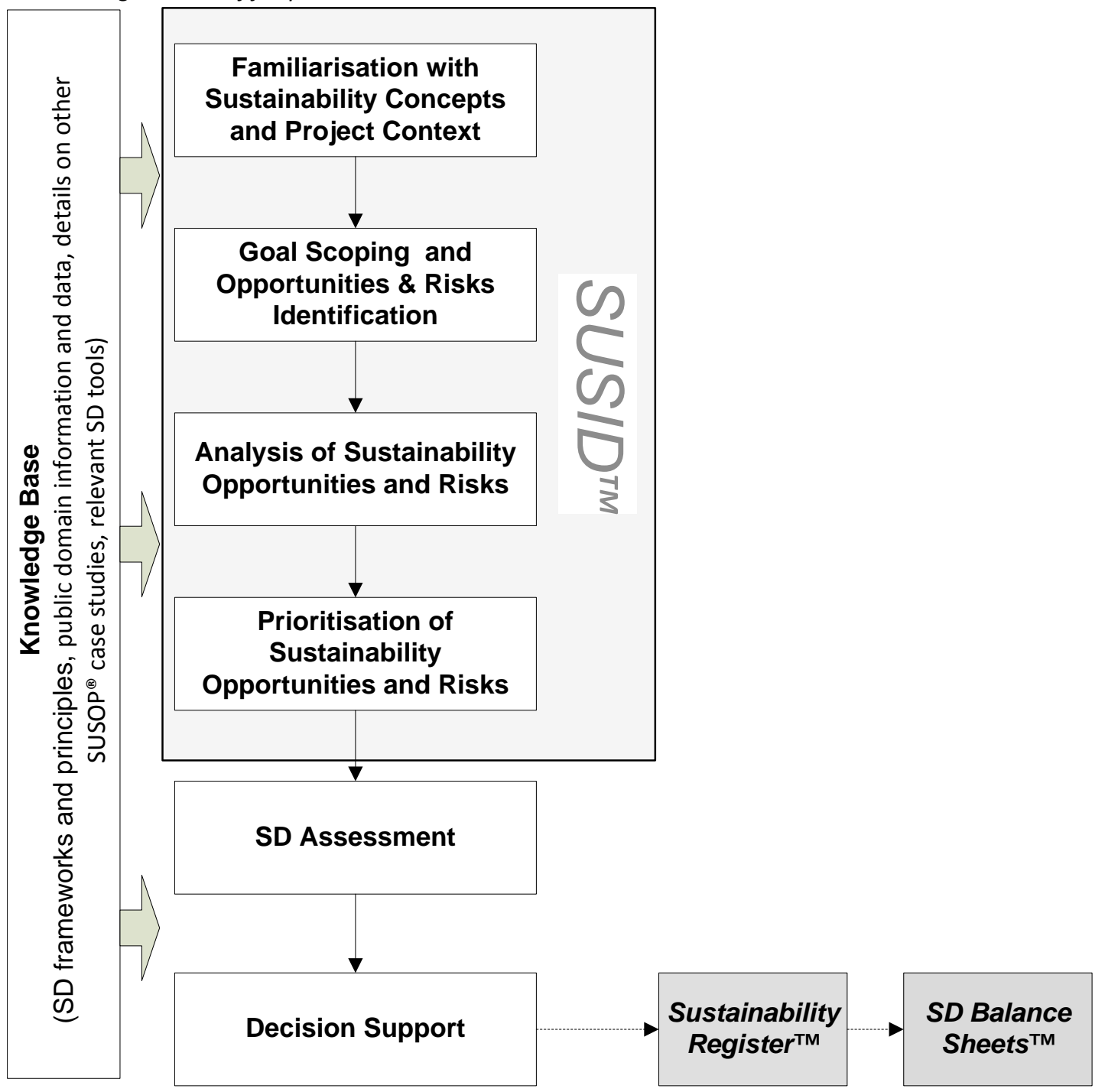

Figure 2: SUSOP ${ }^{\circledR}$ framework

The overall framework of SUSOP ${ }^{\circledR}$ is illustrated in Figure 2. In the SUSID"M element, the "Five Capitals" model - natural, manufactured, financial, human and social capitals [34] - is utilized for the identification and classification of opportunities and risks. The "Five Capitals" model provides a basis for understanding sustainability in terms of the economic concept of wealth creation or 'capital' [34] and supplies an effective overarching structure within SUSOP ${ }^{\circledR}$ for drawing linkages between the various operations and stakeholders involved in the development of the project (including various aspects of the environment as a stakeholder as per [43]).

The identification of opportunities and risks is one of the key steps in applying the SUSOP ${ }^{\circledR}$ framework. If the sustainable development contribution of the operation is to be enhanced, then risks (especially major risks) must be identified and eliminated or mitigated. In practice, it was found 
McLellan, B.C., Corder, G.D., Risk reduction through early assessment and integration of sustainability in design in the minerals industry, Journal of Cleaner Production, 53( ), 37-46 (2013)

http://dx.doi.org/10.1016/j.jclepro.2012.02.014.

that identifying opportunities for beneficial innovation is the more challenging aspect of the process

- risks became apparent without much prompting.

All elements are supported by the SUSOP ${ }^{\circledR}$ Knowledge Base which includes information on sustainability frameworks and principles, details on case studies, relevant SD tools and databases to assist in the evaluation and assessment stages, resources for workshops and relevant public domain information and data.

The main outputs from a SUSOP ${ }^{\circledR}$ study are presented in the Sustainability Register ${ }^{\mathrm{TM}}$, which works is a similar manner to the conventional risk register. The Sustainability Register ${ }^{\mathrm{TM}}$ includes opportunities for improving the contribution to societal sustainability and business performance of the project, sustainability risks that could potentially impact on the project's viability and action plans for each item before proceeding through the next project toll gate. Supporting SD Balance Sheets ${ }^{\mathrm{TM}}$ are also given for top ranking opportunities to schematically show the positive and negative impacts across the chosen sustainability framework.

The SD Balance Sheet ${ }^{\mathrm{TM}}$, shown in Figure 3, is used to allow the project team and final decision makers to visualize the benefits or negative impacts of incorporating a variety of sustainability opportunities (as identified in SUSID ${ }^{\mathrm{TM}}$ ). It has proved an effective manner for communicating the outcomes from applying the SUSOP ${ }^{\circledR}$ framework, by showing graphically the potential positive and negative impacts of the opportunities and risks compared with the business-as-usual approach categorized in each of the "Five Capitals". The impact ratings are similar to a consequence rating used in a typical risk based approach, where a -5 rating has widespread and/or catastrophic results and a $(+) 5$ rating has widespread benefits to a broad range of stakeholders. Alternative communication tools such as "radar diagrams" [44], quadrant graphing [45], combined graphical and text displays [46] or mapping tools [47] may be used, but the key feature must be to express the relative improvement and absolute performance of different design options. 
McLellan, B.C., Corder, G.D., Risk reduction through early assessment and integration of sustainability in design in the minerals industry, Journal of Cleaner Production, 53( ), 37-46 (2013)

http://dx.doi.org/10.1016/j.jclepro.2012.02.014.
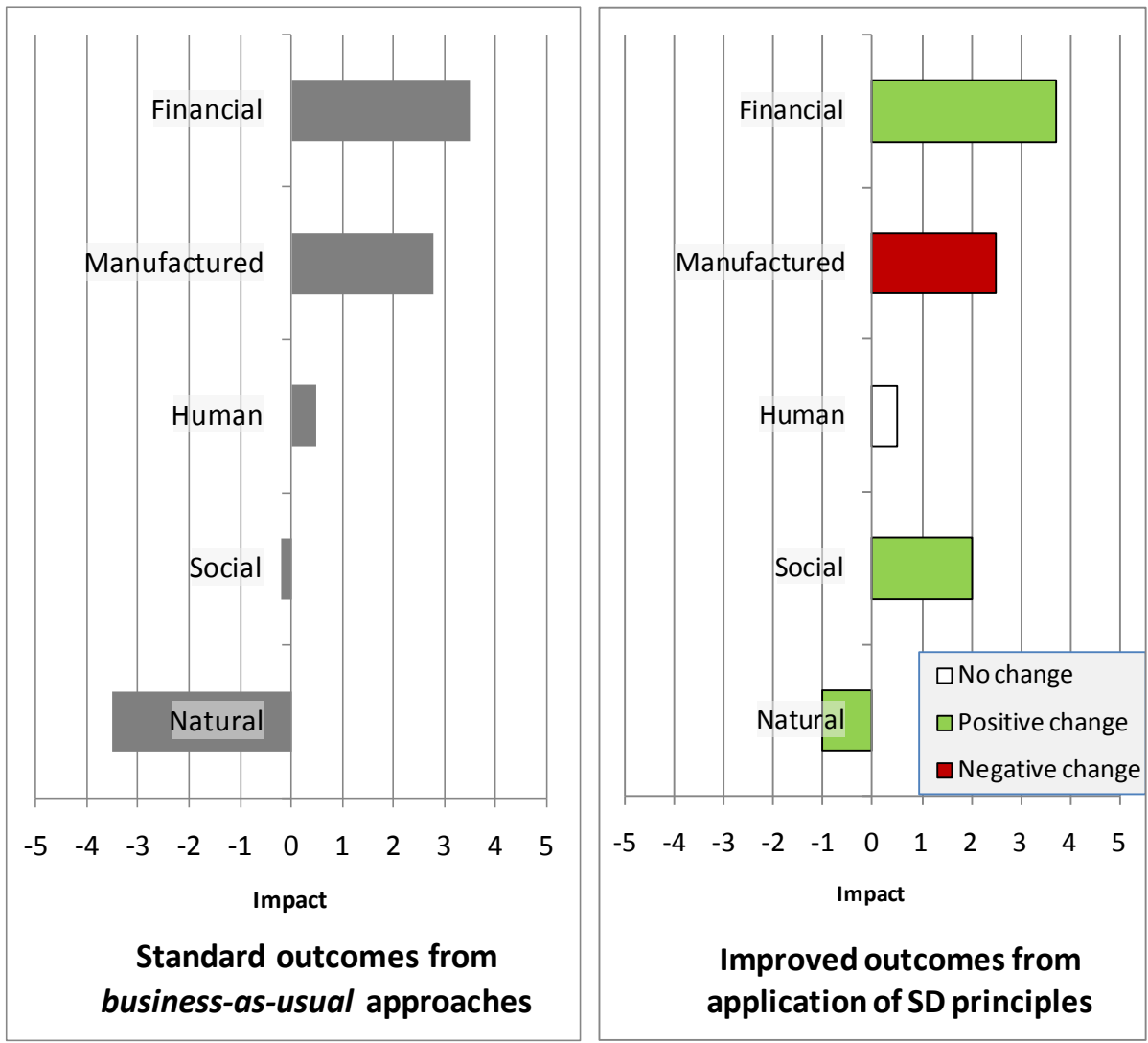

Figure 3: SD Balance Sheet ${ }^{\mathrm{TM}}$ Example (Note: change is capital for application of SD principles is relative to respective capital in business-as-usual)

The participants in a SUSOP ${ }^{\circledR}$ study will vary depending on the stage that the project is at and the type of project being considered. Typically core project staff (e.g. process engineers and plant designers) plus environmental and community experts are part of the SUSOP ${ }^{\circledR}$ study team. This diversity, and the inclusion of lateral thinkers, greatly enhances the potential for generating innovative and alternative opportunities as well as identifying possible sustainability risks. For the assessment of SD risk reduction in this paper, such broad expertise was enlisted.

\section{Case Studies}

Two case studies are used as examples of the interaction of sustainable development improvements, cleaner production and risk reduction. The case studies that have been completed under the SUSOP ${ }^{\circledR}$ framework have fallen into the project stages of "concept" and "pre-feasibility", and covered the production stages of extraction, processing and refining. The current analysis is therefore only representative of these stages. However, the fact that these stages have the highest 
McLellan, B.C., Corder, G.D., Risk reduction through early assessment and integration of sustainability in design in the minerals industry, Journal of Cleaner Production, 53( ), 37-46 (2013)

http://dx.doi.org/10.1016/j.jclepro.2012.02.014.

practical potential to influence the final operation sustainability of the project, make these case studies particularly significant.

In order to maintain client confidentiality, specific details on each case study have not been included. The studies are described briefly below.

\subsection{Case study 1 (CS1)}

Case study 1 (CS1) examined sustainable development risks and opportunities as a potential differentiator between alternative sites for a "greenfields" mine - processing plant - refinery export infrastructure" project. The location was in a developing country with sensitive environments, low skills development, high political instability and a scarcity of non-mineral resources.

Due to pending expiration of retention leases, the developer was faced with a deadline for site selection. Through employing standard business practices the developer could not provide definitive guidance on which sites to retain and which to relinquish. As a result, SUSOP ${ }^{\circledR}$ was applied in an attempt to make this distinction on a sustainability basis.

An initial SUSID ${ }^{\mathrm{TM}}$ workshop was held to identify the sustainability goals and opportunities related to each of the proposed locations. Participants comprised members from the SUSOP ${ }^{\circledR}$ research team plus company personnel and their consultant engineers (who had worked on the environmental and social aspects of this project). From SUSID ${ }^{\mathrm{TM}}$, nearly 70 possible sustainability opportunities across all aspects of sustainability were identified. These were then grouped into clusters of linked sustainability opportunities to produce an enhanced understanding of dependencies and deliver a better appreciation of the overall potential SD benefits.

High imported fossil fuel costs and high expatriate labor costs were considered high priority business risks that could prevent the operation from being in the lowest operating cost quartile. Furthermore, a variety of risks associated with high volume tailings and potential impacts of the operation on endangered species were identified, with sustainable design options proposed to mitigate or reduce these risks.

\subsection{Case study 2 (CS2)}

Case study 2 applied sustainable development principles to the evaluation and improvement of waste treatment options for a processing plant expansion project. The existing plant was looking to extract more metal per year, requiring a facility expansion. The expanded process would include new 
McLellan, B.C., Corder, G.D., Risk reduction through early assessment and integration of sustainability in design in the minerals industry, Journal of Cleaner Production, 53( ), 37-46 (2013)

http://dx.doi.org/10.1016/j.jclepro.2012.02.014.

technology and expanded waste production, which could not be treated at the current facility. The operation was in an area of low-mid development, with a relatively skilled workforce and some alternative industry. The operating company wanted to examine the sustainability performance of a range of proposed effluent treatment options at a mineral processing operation. The aim of this case study was to apply the SUSOP ${ }^{\circledR}$ mechanism to identify sustainability opportunities and evaluate the sustainability performance of the proposed options.

An initial SUSID ${ }^{\mathrm{TM}}$ workshop was held to identify the sustainability goals and opportunities related to each of the effluent treatment options. Members from the SUSOP research team plus representatives from the operating company and their engineering consultants (who previously undertook an engineering study of the different effluent treatment technologies) participated in the workshop. A detailed analysis of the identified sustainability opportunities related to the effluent options was then conducted by the SUSOP ${ }^{\circledR}$ research team ahead of the 2-day prioritisation workshop. A shortlist of key sustainability opportunities that demonstrate the sustainability benefits and impacts of the effluent treatment options were agreed on at the end of the prioritisation workshop.

\subsection{Comparison of Case Studies}

The bounds for interpretation of the results must further be narrowed, as the case studies both come from the application of one framework for sustainable design - SUSOP ${ }^{\circledR}$. Both case studies involved base metals extraction, processing and refining, were located in (different) low-mid development countries that have potential for political instability and are sensitive to environmental conditions. These conditions are not seen as barriers to extrapolating from the results however, as they are considered to be indicative of the potential for risk mitigation through integrating sustainable development principles in design. These case studies are considered to be ideal examples, in that they cover the emerging frontier of the minerals industry-developing countries, sensitive environments and political instability.

The two case studies were also quite different in the scope of the study. CS1 had a broad scope to examine all aspects of the project, while CS2 was specifically focused on the waste and effluent treatment operations. The wider scope of CS1 led to wider opportunities identification and facilitated the incorporation of sustainable development aspects, whereas in CS2 the tight scope tended to restrict the ability to connect multiple capitals in the opportunities identified.

Perhaps the most important aspect of these case studies is that they were the result of applying the SUSOP ${ }^{\circledR}$ framework to real projects (as opposed to purely theoretical analysis). Thus the 
McLellan, B.C., Corder, G.D., Risk reduction through early assessment and integration of sustainability in design in the minerals industry, Journal of Cleaner Production, 53( ), 37-46 (2013)

http://dx.doi.org/10.1016/j.jclepro.2012.02.014.

learnings have potential to help bridge the gap between academic and commercial consideration of sustainability in industrial design.

\section{Results and Discussion}

\subsection{Generic SD-risks in the minerals industry}

The first stage of examination of sustainability risk identification and mitigation using the SUSOP ${ }^{\circledR}$ framework was to look at the theoretical categories of risk that were common to the case studies. Figure 4 gives a generalized picture of the systems examined in the two case studies, showing some of the major flows into and out of the system. This flowsheet is also indicative of minerals industry operations in general. The identification of opportunities and risks for sustainability followed a structured examination of each of the key flows and processes, to determine their impact on the each of the capitals in the "Five Capitals" model.

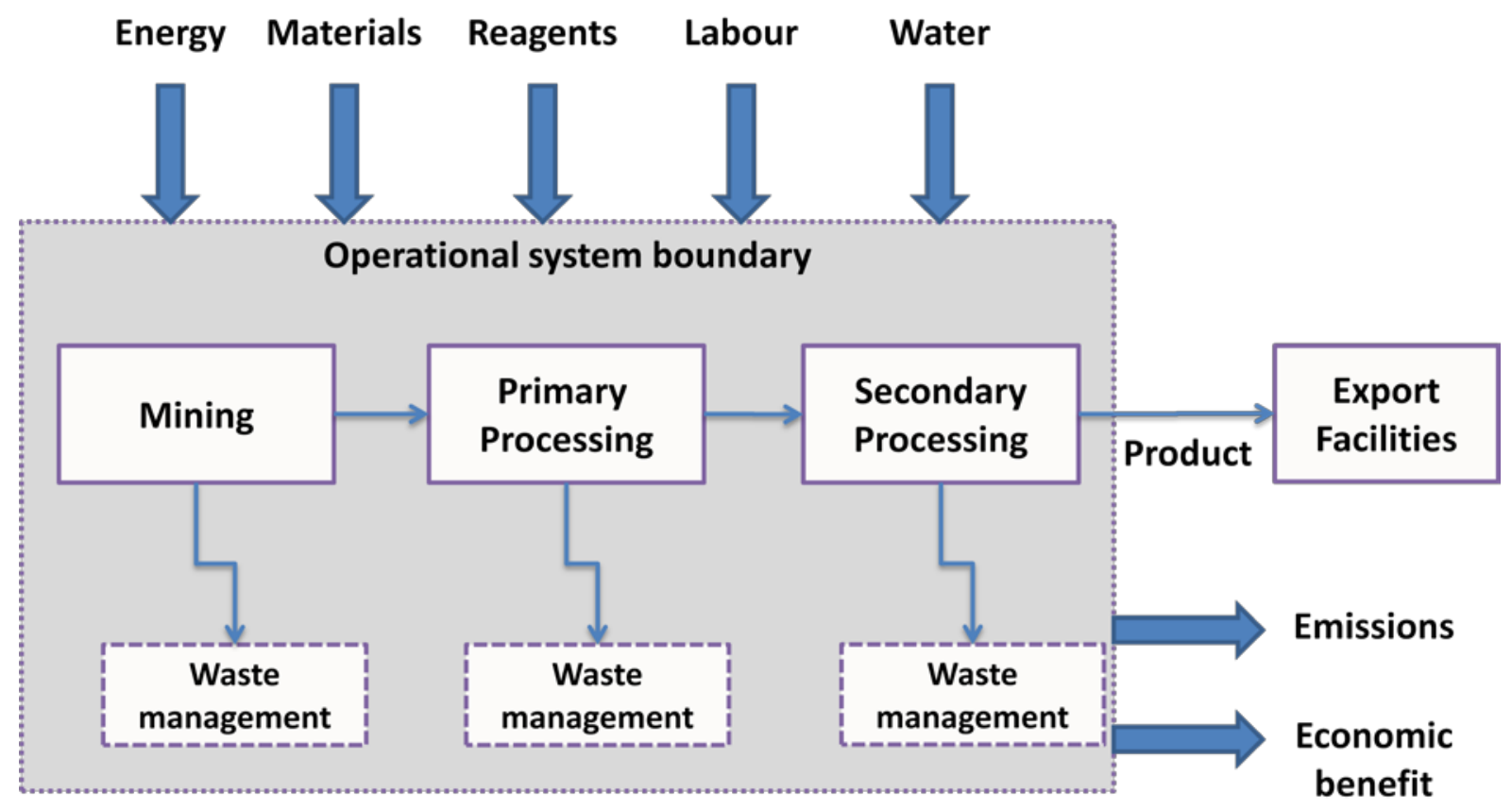

Figure 4: Generalised system boundary for operational risk consideration

A list of some of the identified generic risks associated with the inputs, internal operations and outputs of the project and the major capital with which that risk is associated were identified and are presented in Table 3. (This list is not comprehensive, but covers major SD-risks). Primary and secondary processing were combined in this assessment, because the generic risks are quite similar (although the specific risks associated with the different magnitude and toxicity of flows will obviously differ [4]). 
McLellan, B.C., Corder, G.D., Risk reduction through early assessment and integration of sustainability in design in the minerals industry, Journal of Cleaner Production, 53( ), 37-46 (2013)

http://dx.doi.org/10.1016/j.jclepro.2012.02.014.

Table 3: Generic risks associated with the case studies

\begin{tabular}{|c|c|c|c|c|}
\hline \multirow[t]{2}{*}{ Operation } & \multicolumn{3}{|c|}{ Risks associated with: } & \multirow{2}{*}{$\begin{array}{l}\text { Risk effects on } \\
\text { capital: }\end{array}$} \\
\hline & Inputs & $\begin{array}{l}\text { Internal } \\
\text { operations }\end{array}$ & Output & \\
\hline $\begin{array}{l}\text { Mining } \\
\text { Inputs: Fuel, equipment, labor, } \\
\text { materials, explosives; }\end{array}$ & $\begin{array}{l}\text { Energy; } \\
\text { Explosives; }\end{array}$ & $\begin{array}{l}\text { Land use } \\
\text { degradation; }\end{array}$ & $\begin{array}{l}\text { Land use } \\
\text { degradation; } \\
\text { Potential } \\
\text { leachate } \\
\text { impacts; }\end{array}$ & Natural \\
\hline \multirow[t]{2}{*}{$\begin{array}{l}\text { Internal: Blasting, excavation, } \\
\text { hauling; }\end{array}$} & & $\begin{array}{l}\text { Equipment } \\
\text { damage; }\end{array}$ & & Manufactured \\
\hline & $\begin{array}{l}\text { Explosives; } \\
\text { Employment; }\end{array}$ & (Safety) & Health impacts; & Human \\
\hline \multirow{2}{*}{$\begin{array}{l}\text { Outputs: Ore, waste rock, air } \\
\text { emissions (dust and fuel } \\
\text { emissions); }\end{array}$} & $\begin{array}{l}\text { Employment; } \\
\text { Purchasing } \\
\text { policies; }\end{array}$ & $\begin{array}{l}\text { Loss of traditional } \\
\text { land use; }\end{array}$ & $\begin{array}{l}\text { Loss of } \\
\text { traditional land } \\
\text { use; }\end{array}$ & Social \\
\hline & $\begin{array}{l}\text { Energy (cost); } \\
\text { Labor cost; }\end{array}$ & & $\begin{array}{l}\text { Product market } \\
\text { price and } \\
\text { demand; }\end{array}$ & Financial \\
\hline $\begin{array}{l}\text { Primary / secondary processing } \\
\text { Inputs: Fuel, equipment, labor, } \\
\text { materials, reagents; }\end{array}$ & $\begin{array}{l}\text { Energy; } \\
\text { Reagents; }\end{array}$ & & $\begin{array}{l}\text { Land use } \\
\text { degradation - } \\
\text { Tailings; } \\
\text { Effluent impacts; }\end{array}$ & Natural \\
\hline $\begin{array}{l}\text { Internal: Crushing / grinding; } \\
\text { hydrometallurgical processing; }\end{array}$ & $\begin{array}{l}\text { Material } \\
\text { availability; }\end{array}$ & $\begin{array}{l}\text { Process } \\
\text { conditions; }\end{array}$ & & Manufactured \\
\hline Pyrometallurgical processing; & $\begin{array}{l}\text { Reagents; } \\
\text { Employment; }\end{array}$ & (Safety) & $\begin{array}{l}\text { Health impacts } \\
\text { on community; }\end{array}$ & Human \\
\hline $\begin{array}{l}\text { Outputs: Tailings, concentrate / } \\
\text { primary product, final metal } \\
\text { product, effluent, emissions; }\end{array}$ & $\begin{array}{l}\text { Employment; } \\
\text { Purchasing } \\
\text { policy; } \\
\text { Political }\end{array}$ & $\begin{array}{l}\text { Discrimination or } \\
\text { lack of equity; }\end{array}$ & $\begin{array}{l}\text { Loss of } \\
\text { traditional land } \\
\text { use; }\end{array}$ & Social \\
\hline
\end{tabular}


McLellan, B.C., Corder, G.D., Risk reduction through early assessment and integration of sustainability in design in the minerals industry, Journal of Cleaner Production, 53( ), 37-46 (2013) http://dx.doi.org/10.1016/j.jclepro.2012.02.014.

\begin{tabular}{|l|l|l|l|l|}
\hline & instability; & & & \\
\cline { 2 - 5 } & Energy cost; & & $\begin{array}{l}\text { Product market } \\
\text { price and } \\
\text { demand; }\end{array}$ & Financial \\
& Reagent cost; & & & \\
& Labor cost; & & & \\
\hline
\end{tabular}

The risks in Table 3 are representative of the types of SD-risks that the SUSOP ${ }^{\circledR}$ framework is used to identify and mitigate through sustainable design. The SUSOP ${ }^{\circledR}$ framework uses a group of experts consisting of both technical and sustainability professionals to examine the risks arising from each operation and flow. For the two case studies under consideration, the results of their analysis indicated that the key areas of concern were:

- Energy - security, cost and greenhouse gas emissions

- Labor - cost, skills availability in local area, social impacts

- Solid waste - in particular tailings

- Effluent - cost of treatment, impact of treatment failure and treatment co-products

Energy is a particular concern within the minerals industry, as much of the lifetime energy for production of metal products is used in the production of primary refined metal [48-50]. With regards to the energy risks, CS1 was particularly sensitive to all three elements (security, cost and greenhouse gas emissions) due to the need to import fossil fuels. For CS1, opportunities were identified for the development of a local renewable energy industry - based on sustainable biomass harvesting, solar, geothermal and tidal power. This was linked with the training and skills development of technicians over a ten year period in the lead-up to construction of the operation which would reduce the need to import expensive expatriate labor [29]. The benefit of such a program would impact the local community and significantly increase human and social capital, thereby potentially significantly enhancing the Social License to Operate for the company.

In CS2, potential reduction in energy consumption was addressed through recovery of waste heat from primary processing operations to power effluent treatment technologies, thereby reducing the cost of fuel and reducing associated carbon emissions.

One of the most important areas of potential risk and improvement for sustainable minerals processing operations is solid waste and tailings management [4]. Although the placement and containment of tailings is particularly closely studied in the development of minerals projects, the 
McLellan, B.C., Corder, G.D., Risk reduction through early assessment and integration of sustainability in design in the minerals industry, Journal of Cleaner Production, 53( ), 37-46 (2013)

http://dx.doi.org/10.1016/j.jclepro.2012.02.014.

decision and design process is largely based on an "end-of-pipe" approach. During the case studies examined here, the issue was examined from the broader perspective of sustainability and the potential uses of the waste products were examined as an industrial synergy. In both case studies, the potential for the usage of tailings (with some pre-treatment) as a cement substitute was highlighted. In particular for CS1, the area of the operation had little local infrastructure and little available cement, so the synergy, and the ability to create local enterprise development was a highly rated opportunity. In the case of some minerals waste - especially fly ash, slags and bauxite residue - there is potential for use as geopolymers which may be able to mitigate some of the carbon dioxide emissions associate with traditional cement production [51, 52]. Naturally, it is likewise important to examine the potential impacts of these materials in the proposed applications, as the potential for leaching of hazardous substances may be a barrier to implementation $[53,54]$.

Effluent treatment options for both case studies contained some interlinking with the treatment and storage of solid wastes. The selection of effluent treatment options was the key criteria associated with CS2. The severity of risk associated with effluent is related to its volume, toxicity and transmission to receptors. Typical effluent treatment in the minerals industry (as with most industries) is guided by health and environmental release guidelines, to which minerals operations should and will conform. The ideal solution for effluent treatment is not to produce the effluent in the first place, by implementing alternative technologies that do not create large effluent streams. However, where this is not possible, effluent toxicity can be reduced by changing process reagents or by removing certain species from the effluent stream. Ultimately however, in most operations (as in CS2) there is a remaining effluent stream that must be treated. From the perspective of likelihood, the prevention of uncontrolled release or the potential to mitigate overflow situations had to be considered.

Utilizing sustainability principles, through the SUSOP ${ }^{\circledR}$ framework, as a basis for assessing and identifying opportunities associated with a number of effluent treatment options in CS2 produced the following results:

- Using accepted company sustainability reporting metrics, the different options were analysed and compared using a risk-based approach (probability of impact or benefit versus likelihood).

- Improved integration of waste energy from the processing facility to drive treatment processes was recommended in all cases, which assisted in mitigating some of the high costs of treatment. 
McLellan, B.C., Corder, G.D., Risk reduction through early assessment and integration of sustainability in design in the minerals industry, Journal of Cleaner Production, 53( ), 37-46 (2013) http://dx.doi.org/10.1016/j.jclepro.2012.02.014.

- Treatment options that created beneficial by-products and the opportunity to market or process these through new social enterprise development were favored.

- All treatment options included sufficient buffering capacity to account for oversupply or flooding events.

- The precautionary approach was applied to all substance releases - regardless of the recommended water content guidelines.

\subsection{Analysis of Mitigating Strategies}

The key outcomes for both CS1 and CS2 of the SD risk and opportunities identification process are summarized in Table 4. 
McLellan, B.C., Corder, G.D., Risk reduction through early assessment and integration of sustainability in design in the minerals industry, Journal of Cleaner Production, 53( ), 37-46 (2013)

http://dx.doi.org/10.1016/j.jclepro.2012.02.014.

Table 4: Sustainability-based risk reduction strategies

\begin{tabular}{|c|c|c|c|}
\hline Motivating risk & Risk reduced & Outcome & $\begin{array}{l}\text { Relevant } \\
\text { case study }\end{array}$ \\
\hline $\begin{array}{l}\text { Avoid or minimize } \\
\text { tailings storage }\end{array}$ & $\begin{array}{l}\text { Tailings dam failure; } \\
\text { Financial cost of } \\
\text { storage; } \\
\text { Lack of local supply } \\
\text { and cost of cement; }\end{array}$ & $\begin{array}{l}\text { Utilise tailings as feedstock for new } \\
\text { geopolymer industry or in other } \\
\text { construction materials; }\end{array}$ & $\begin{array}{l}\text { CS1 and } \\
\text { CS2 }\end{array}$ \\
\hline $\begin{array}{l}\text { Labor cost and } \\
\text { skills availability }\end{array}$ & $\begin{array}{l}\text { Financial and } \\
\text { operational risk of } \\
\text { skilled labor } \\
\text { shortage; }\end{array}$ & $\begin{array}{l}\text { Reduce or avoid expensive expatriate } \\
\text { labor force by a gradual training of local } \\
\text { technicians from concept stage till } \\
\text { operation (10 years) }\end{array}$ & CS1 \\
\hline $\begin{array}{l}\text { Energy security, } \\
\text { cost and carbon } \\
\text { intensity }\end{array}$ & $\begin{array}{l}\text { Financial risk of fuel } \\
\text { cost increases; } \\
\text { Risk of skilled labor } \\
\text { shortage; } \\
\text { Risk of climate } \\
\text { change penalties; }\end{array}$ & $\begin{array}{l}\text { Gradual roll-out and integration of locally } \\
\text { produced renewable energy into project } \\
\text { and local community from concept stage; } \\
\text { Training and development of local } \\
\text { renewable energy provision and service } \\
\text { industry; } \\
\text { Integration of primary-secondary } \\
\text { processing plant waste energy streams to } \\
\text { reduce greenhouse emissions and } \\
\text { reliance on fuel imports; }\end{array}$ & $\begin{array}{l}\text { CS1 and } \\
\text { CS2 }\end{array}$ \\
\hline $\begin{array}{l}\text { Effluent } \\
\text { treatment cost, } \\
\text { failure and waste }\end{array}$ & $\begin{array}{l}\text { Failure due to } \\
\text { oversupply or flood } \\
\text { event; } \\
\text { Cost of energy and } \\
\text { reagents; }\end{array}$ & $\begin{array}{l}\text { Use of internal buffer capacity in the } \\
\text { effluent treatment system to prevent } \\
\text { release due to oversupply event; } \\
\text { Utilisation of waste heat streams from } \\
\text { processing plant to substitute for energy }\end{array}$ & $x^{2}$ \\
\hline
\end{tabular}


McLellan, B.C., Corder, G.D., Risk reduction through early assessment and integration of sustainability in design in the minerals industry, Journal of Cleaner Production, 53( ), 37-46 (2013) http://dx.doi.org/10.1016/j.jclepro.2012.02.014.

\begin{tabular}{|l|l|l|l|}
\hline & & used in treatment processes. & CS2 \\
\hline
\end{tabular}

These case study projects are still in the pre-construction phases and therefore a quantitative assessment of the success of the applied SD-based risk reduction process is unable to be made. However, it is possible to use the semi-quantitative assessment of members of the group of sustainability experts and technical personnel involved as an indicator of the improvements made. In the case of CS2, this assessment was undertaken for the analysis and prioritization of sustainable design options within the SUSOP ${ }^{\circledR}$ process, while for CS1 this was retrospectively undertaken at the completion of SUSID'm.

As a part of the "Analysis of Sustainable Development Opportunities and Risks" element of the SUSOP ${ }^{\circledR}$ studies (see Figure 2), the various options were compared to the "base case" by the workshop participants. This process utilized quantitative and semi-quantitative approaches to identify the benefit or detriment of the proposed sustainability measures over the business as usual situation. The project potential with risk mitigation and sustainable development opportunities was compared to the business as usual situation by applying a risk matrix approach (Table 1) to each potential project configuration. The results of the risk matrix approach - assuming that the project developers will implement the new design features and appropriate management procedures - are presented in Table 5.

Table 5: Qualitative improvement in the SD risk of the case study projects before and after the risk identification process

\begin{tabular}{|l|l|c|c|c|c|c|}
\hline \multicolumn{2}{|c|}{ Case study } & \multicolumn{5}{|c|}{ Risk on the “Five Capitals" } \\
\cline { 3 - 7 } \multicolumn{2}{|c|}{} & Natural & Manufactured & Human & Social & Financial \\
\hline \multirow{2}{*}{ CS1 } & Before & High & Moderate & Moderate & Moderate & High \\
\cline { 2 - 7 } & After & Moderate & Moderate & Low & Moderate & Moderate \\
\hline \multirow{2}{*}{ CS2 } & Before & High & Moderate & Moderate & Moderate & Significant \\
\cline { 2 - 7 } & After & Moderate & Moderate & Moderate & Low & Significant \\
\hline
\end{tabular}

Although the quantitative figures cannot be supplied due to the commercially sensitive nature of the data, some key points of SD risk reduction are listed hereafter. It is hoped that these points, and the opportunities listed in Table 4 will give some understanding of the influences on the group's risk allocations. On a capital-by-capital basis, SD risk was reduced due to SD opportunities that (for example): 
McLellan, B.C., Corder, G.D., Risk reduction through early assessment and integration of sustainability in design in the minerals industry, Journal of Cleaner Production, 53( ), 37-46 (2013) http://dx.doi.org/10.1016/j.jclepro.2012.02.014.

Natural capital

- reduced the volume and toxicity of waste and effluent (such as through production of geopolymers, less intensive processing or appropriate storage and treatment) (potentially up to $100 \%$ depending on market demand and processing technology) (CS1 and CS2)

- reduced energy intensity or the carbon intensity of energy used (possibly up to $85 \%$ carbon intensity assuming shifting from coal to biofuels) (CS1 and CS2)

\section{Manufactured capital}

- enhanced shared or community infrastructure and reduced on-site infrastructure requirements (CS1)

\section{$\underline{\text { Human }}$}

- increased employment potential and skills upgrading locally (mostly CS1)

- reduced potential health risks from plant emissions (mostly CS2)

\section{Social}

- enabled start-up business to act as suppliers and utilize plant by-products in enterprise (CS1 and CS2)

\section{Financial}

- reduced labor and fuel costs (CS1)

- reduced fuel and reagent costs (CS2)

\subsection{Key learnings}

A number of key learnings were taken from the examination of SUSOP ${ }^{\circledR}$ as a risk reduction methodology based on sustainable design principles. Firstly, it was identified that risk and opportunity identification using a sustainability framework can contribute significantly to the reduction of risks across a broader spectrum of stakeholders and impact areas than the business as usual approach. Specifically, sustainable development opportunities may reduce the financial risk of the operation indirectly by reducing liability, but also directly through the reduction of cost and potential to market new products or services. Secondly, in relation to the process of identifying risks and opportunities, it was apparent that for an approach to be effective, a structured method is 
McLellan, B.C., Corder, G.D., Risk reduction through early assessment and integration of sustainability in design in the minerals industry, Journal of Cleaner Production, 53( ), 37-46 (2013)

http://dx.doi.org/10.1016/j.jclepro.2012.02.014.

essential - for sustainability risks no less than for other standard risks. The integrative and cross-

cutting nature of sustainable development also helped in the identification of opportunities and risks that do not emerge in typical "siloed" design. Finally, it was clarified that earlier in the project cycle, with a wider scope for identifying cross-cutting opportunities offers the potential for greater risk reduction. Although the evidence is empirical at this stage, it would be hoped that the increasing availability of case studies as sustainable development is more widely integrated in design would confirm these learnings.

\subsection{Insights for Risk and Cleaner Production}

Cleaner production in essence seeks to improve the environmental performance (reduce environmental risk) of an operation or product, often to the benefit of the financial bottom-line. The application of cleaner production in design thus represents an expansion of the traditional risk considerations, which largely focus on financial and safety risks to a business. The further extension of cleaner production to consider the multiple pillars of sustainability (as analysed in this paper) encourages designers to look for opportunities to avoid or mitigate risks through design selection, or to convert risks into opportunities through expanding the boundaries of consideration to incorporate community needs and potential. This may be considered a form of enterprise risk management (as described elsewhere [55]) taken to the broadest possible extent - incorporating both internal and external risks to the operation [42].

The case studies described here have demonstrated cleaner production solutions that have attractive business cases - reducing environmental risk while maintaining or reducing financial risk. The identification of these solutions would not have occurred without a broadening of the cleaner production approach from techno-environmental to a sustainability basis, as many of these opportunities are cross-cutting (integrating various disciplines and design across operational boundaries). This is a key insight for cleaner production - as the reduction of environmental risk can be facilitated by a consideration of social, human and manufactured capital risks.

An additional insight for the implementation of cleaner production is the enabling potential of synergizing sustainability risk assessment with existing processes. The key example of this from the SUSOP ${ }^{\circledR}$ case studies is the integration of sustainability risks into the regular project risk register. As a standalone process, the identified risks and opportunities highlighted through cleaner production assessment may be overlooked - however, by incorporating with the mainstream project processes, acceptance (or at least acknowledgement) is facilitated. 
McLellan, B.C., Corder, G.D., Risk reduction through early assessment and integration of sustainability in design in the minerals industry, Journal of Cleaner Production, 53( ), 37-46 (2013) http://dx.doi.org/10.1016/j.jclepro.2012.02.014.

A final insight on the ability to engage actual industrial case studies was the desire to reduce risk as a motivation for the uptake of cleaner production. In this paper, company requirement to reduce risk of project failure through social backlash or environmental breaches was a key driver in the initiation of the case studies. Cleaner production (or SUSOP ${ }^{\circledR}$ in this case) offers one tool to mitigate such risks, and was thus sought out by the operators. Success in identifying risk reduction opportunities (as demonstrated by these case studies) is expected to further improve demand for cleaner production studies.

\section{Conclusions}

This paper has outlined the application of a methodology for improving the sustainability performance of minerals operations and the possibilities for SD risk reduction through such an approach. By adopting a structured process and overarching sustainability model, it is possible to not only identify potential sustainability risks but develop opportunities or strategies that can greatly help mitigate these risks. This approach was applied to two case studies that involved base metals extraction and processing and were located in low-mid development countries. Initiatives or strategies to mitigate the identified risks related to energy, labor, solid waste and effluent included the gradual roll-out and integration of locally produced renewable energy, skills training and capacity building with the local workforce, creation of a new 'green' construction industry and enterprise development within the local community.

Comparing the potential risks before and after implementation of the sustainable design features, it is apparent that in some cases there is an expected decrease in the level of risk. This is true largely in regard to Natural, Human and Social capital. The risks associated with political instability with mining in the case study countries plus the volatility of some base metal commodity markets mean that it is difficult to identify opportunities or initiatives that can, on balance, ensure a significant reduction in risk for Financial and Social capitals - although the flow-on effects of increased skills and employment and the reduction of imports of energy would contribute to this. Risk reduction to manufactured capital may arise as an indirect benefit of identified opportunities that reduce the chemical or physical extremity of process conditions, however no significant manufactured capital risk reduction was observed in this study.

Using such an approach makes it possible to consider risks that might jeopardize the principles of sustainability early on in the development of a new minerals project. In doing so, the resulting 
McLellan, B.C., Corder, G.D., Risk reduction through early assessment and integration of sustainability in design in the minerals industry, Journal of Cleaner Production, 53( ), 37-46 (2013)

http://dx.doi.org/10.1016/j.jclepro.2012.02.014.

initiatives or strategies to mitigate these risks play an important part in enhancing the social license to operate of the resulting minerals operation.

\section{Acknowledgements}

The case study projects and the development of SUSOP ${ }^{\circledR}$ was carried out under the auspice and with the financial support of the Cooperative Research Centre for Sustainable Resource Processing (www.csrp.com.au), which is established and supported under the Australian Government's Cooperative Research Centres Program.

\section{References}

[1] Mudd GM. Global trends in gold mining: Towards quantifying environmental and resource sustainability. Resources Policy. 2007;32(1-2):42-56.

[2] Mudd GM. The Environmental sustainability of mining in Australia: key mega-trends and looming constraints. Resources Policy. 2010;35(2):98-115.

[3] Emel J, Huber MT. A risky business: Mining, rent and the neoliberalization of "risk". Geoforum. 2008;39(3):1393-407.

[4] Broadhurst JL, Petrie JG. Ranking and scoring potential environmental risks from solid mineral wastes. Minerals Engineering. 2010;23(3):182-91.

[5] Stenson J. Disaster management as a tool for sustainable development: a case study of cyanide leaching in the gold mining industry. Journal of Cleaner Production. 2006;14(3-4):230-3.

[6] GRI. An Abridged Version of the 2002 Sustainability Reporting Guidelines: Integrated with the Draft Mining and Metals Sector Supplement. Amsterdam, The Netherlands: International Council of Mining and Minerals; 2004. p. 39 pages.

[7] GRI. Sustainability Reporting Guidelines. In: GRI, editor. Amsterdam, Netherlands: Global Reporting Initiative; 2006.

[8] Poplin GS, Miller HB, Ranger-Moore J, Bofinger CM, Kurzius-Spencer M, Harris RB, et al. International evaluation of injury rates in coal mining: A comparison of risk and compliance-based regulatory approaches. Safety Science. 2008;46(8):1196-204.

[9] Pitblado R. Global process industry initiatives to reduce major accident hazards. Journal of Loss Prevention in the Process Industries.In Press, Corrected Proof.

[10] Kecojevic V, Komljenovic D, Groves W, Radomsky M. An analysis of equipment-related fatal accidents in U.S. mining operations: 1995-2005. Safety Science. 2007;45(8):864-74.

[11] Komljenovic D, Groves WA, Kecojevic VJ. Injuries in U.S. mining operations - A preliminary risk analysis. Safety Science. 2008;46(5):792-801.

[12] Groves WA, Kecojevic VJ, Komljenovic D. Analysis of fatalities and injuries involving mining equipment. Journal of Safety Research. 2007;38(4):461-70.

[13] Kletz T. Incidents that could have been prevented by HAZOP. Journal of Loss Prevention in the Process Industries. 1991;4(2):128-9.

[14] Kletz TA. The Origins and History of Loss Prevention. Process Safety and Environmental Protection. 1999;77(3):109-16.

[15] Wu DD, Olson D. Enterprise risk management: a DEA VaR approach in vendor selection. International Journal of Production Research. 2010;48(16):4919 - 32. 
McLellan, B.C., Corder, G.D., Risk reduction through early assessment and integration of sustainability in design in the minerals industry, Journal of Cleaner Production, 53( ), 37-46 (2013)

http://dx.doi.org/10.1016/j.jclepro.2012.02.014.

[16] Juan Garcia-Serna JLMMJC. Green HAZOP Analysis: Incorporating Green Engineering into Design, Assessment and Implementation of Chemical Processes. ChemInform. 2007;38(27).

[17] ICMM. Maximising Value: Guidance on implementing materials stewardship in the minerals and metals value chain. London: International Council on Mining \& Metals; 2006.

[18] ICMM. Sustainable Development Framework. In: ICMM, editor. London: International Council on Mining and Metals; 2010.

[19] IIED, WBCSD. Breaking new ground: Mining, minerals and sustainable development. Mining Minerals and Sustainable Development Project: International Institute for Environment and Development and World Business Council for Sustainable Development; 2002.

[20] IISD. Seven questions to sustainability: how to assess the contribution of mining and minerals activities. Winnipeg (Ma), Canada: International Institute for Sustainable Development; 2002. [21] Laurence D. Establishing a sustainable mining operation: an overview. Journal of Cleaner Production. 2011;19(2-3):278-84.

[22] Sandoval MC, Veiga MM, Hinton J, Sandner S. Application of sustainable development concepts to an alluvial mineral extraction project in Lower Caroni River, Venezuela. Journal of Cleaner Production. 2006;14(3-4):415-26.

[23] Finnie B, Stuart J, Gibson L, Zabriskie F. Balancing environmental and industry sustainability: A case study of the US gold mining industry. Journal of Environmental Management. 2009;90(12):3690-9.

[24] van Berkel R. Cleaner production and eco-efficiency initiatives in Western Australia 1996-2004. Journal of Cleaner Production. 2007;15(8-9):741-55.

[25] van Berkel R. Sustainable development and cleaner production in minerals and energy production. Sixth international symposium on environmental issues and waste management in energy and mineral production. Calgary, Canada2000.

[26] van Beers D, Corder GD, Bossilkov A, van Berkel R. Regional Synergies in the Australian Minerals Industry: Case-Studies and Enabling Tools. Minerals Engineering. 2007;20:830-41.

[27] Burke E. Corporate Community Relations: The Principle of Neighbour of Choice. London: Praeger; 1999.

[28] Mudd G. Sustainability Reporting and Mining. Sustainable development indicators in the minerals industry (SDIMI 2009). Gold Coast, Australia: Australasian Institute of Mining and Metallurgy (AUSIMM); 2009. p. 377-91.

[29] Corder G, McLellan B, Bangerter PJ, van Beers D, Green S. Engineering-in sustainability: Learnings from the application of SUSOP(R). Chemeca 2010 - Engineering at the Edge. Adelaide, Australia: Engineers Australia and the Institution of Chemical Engineers Australia; 2010. p. Session 55.

[30] Green S, Corder G, McLellan B, van Beers D, Bangerter PJ. SUSOP(R): Embedding sustainable development principles into the design and operation of resource extraction and processing operations. Sustainable Mining Conference 2010. Kalgoorlie, Australia: Australasian Institute of Mining and Metallurgy; 2010. p. Paper 48.

[31] Corder GD, McLellan BC, Green SR. Delivering solutions for resource conservation and recycling into project management systems through SUSOP ${ }^{\circledR}$. Minerals Engineering. 2011(0).

[32] Corder GD, McLellan BC, Green S. Incorporating sustainable development principles into minerals processing design and operation: SUSOP ${ }^{\circledR}$. Minerals Engineering. 2010;23(3):175-81.

[33] Foerstl K, Reuter C, Hartmann E, Blome C. Managing supplier sustainability risks in a dynamically changing environment-Sustainable supplier management in the chemical industry. Journal of Purchasing and Supply Management. 2010;16(2):118-30.

[34] FF. Forum for the Future Website. Forum for the Future; 2005.

[35] Petrie J. New Models of Sustainability for the Resources Sector: A Focus on Minerals and Metals. Process Safety and Environmental Protection. 2007;85(1):88-98. 
McLellan, B.C., Corder, G.D., Risk reduction through early assessment and integration of sustainability in design in the minerals industry, Journal of Cleaner Production, 53( ), 37-46 (2013)

http://dx.doi.org/10.1016/j.jclepro.2012.02.014.

[36] Petrie J, Cohen B, Stewart M. Decision support frameworks and metrics for sustainable development of minerals and metals. Clean Technologies and Environmental Policy. 2007;9(2):13345.

[37] Azapagic A. Indicators of sustainable development for the minerals extraction industry: environmental considerations. In: Roberto C. Villas Bôas, Filho LF, editors. Technological challenges posed by sustainable development: the mineral extraction industries: CYTED/IMAAC/UNIDO; 1999. [38] McLellan BC, Corder GD, Giurco D, Green S. Incorporating sustainable development in the design of mineral processing operations - Review and analysis of current approaches. Journal of Cleaner Production. 2009;17(16):1414-25.

[39] McLellan B, Corder G, Green S. Embedding Sustainable Development into the Design and Operation of Industrial Processing Plants. Sustain the Planet - Society for Sustainability and Environmental Engineering Conference, SSEE 2009 Melbourne: Engineers Australia; 2009. [40] AACE. Cost estimate classification system - as applied in engineering, procurement and construction for the process industries. In: AACE, editor. AACE International Recommended Practice: Association for the Advancement of Cost Engineering; 2005.

[41] McLellan BC, Corder GD, Green S. Embedding Sustainable Development into the Design and Operation of Industrial Processing Plants. 2009 SSEE International Conference - Solutions for a Sustainable Planet. Melbourne, Victoria, Australia: Society for Sustainability \& Environmental Engineering; 2009.

[42] Wu DD, Kefan X, Gang C, Ping G. A Risk Analysis Model in Concurrent Engineering Product Development. Risk Analysis. 2010;30(9):1440-53.

[43] Sharratt PN, Choong PM. A life-cycle framework to analyse business risk in process industry projects. Journal of Cleaner Production. 2002;10(5):479-93.

[44] Foran B, Lenzen M, Dey C, Bilek M. Integrating sustainable chain management with triple bottom line accounting. Ecological Economics. 2005;52(2):143-57.

[45] Mackay T, MacMillan G, Gale S, Bangerter P. Sustainability and Steel: a matter of application and innovative design. South African Institute of Steel Construction - 50th Anniversary Conference. Johannesburg2006.

[46] McLellan B, Corder G, Green S. Assessing the Benefits of Sustainable Processing in the Minerals Industry. Chemeca 2007. Melbourne: The Institution of Engineers Australia; 2007.

[47] $M^{c}$ Lellan B. PhD Thesis: Location-Specific Sustainability Metrics for Hydrogen Energy Systems [PhD Thesis]: University of Queensland; 2007.

[48] Norgate T, Rankin W. Life cycle assessment of copper and nickel production. MINPREX 2000. Melbourne, Australia2000. p. 133-8.

[49] Norgate TE, Jahanshahi S, Rankin WJ. Assessing the environmental impact of metal production processes. Journal of Cleaner Production. 2007;15(8-9):838-48.

[50] Giurco D, Petrie JG. Strategies for reducing the carbon footprint of copper: New technologies, more recycling or demand management? Minerals Engineering. 2007;20(9):842-53.

[51] Duxson P, Provis JL, Lukey GC, van Deventer JSJ. The role of inorganic polymer technology in the development of [']green concrete'. Cement and Concrete Research. 2007;37(12):1590-7.

[52] Stengel T, Reger J, Heinz D. Life cycle assessment of geopolymer concrete - what is the environmental benefit? Concrete Solutions 09. Luna Park, Sydney, Australia: Concrete institute of Australia; 2009. p. Paper 6a-4.

[53] Tiruta-Barna L, Benetto E, Perrodin Y. Environmental impact and risk assessment of mineral wastes reuse strategies: Review and critical analysis of approaches and applications. Resources, Conservation and Recycling. 2007;50(4):351-79.

[54] Benetto E, Tiruta-Barna L, Perrodin Y. Combining lifecycle and risk assessments of mineral waste reuse scenarios for decision making support. Environmental Impact Assessment Review.

2007;27(3):266-85.

[55] Wu D, Olson DL. Enterprise risk management: coping with model risk in a large bank. J Oper Res Soc. 2009;61(2):179-90. 